\title{
Análise de produtos desenvolvidos no mestrado profissional na área de matemática: possibilidades de adaptações para o uso com estudantes cegos
}

Analysis of the products developed in the professional mastership in mathematics: possibilities of adaptations in the use with blind students

Análisis de productos desarrollados en la maestría profesional en el área de matemáticas: posibilidades de adaptaciones para el uso con estudiantes ciegos

Lúcia Virginia Mamcasz Viginheski ${ }^{[a]}$, João Paulo Aires ${ }^{[a]}$, Sani de Carvalho Rutz da Silva ${ }^{[a]}$, Luiz Alberto Pilatti ${ }^{[a]}$, Antonio Carlos Frasson ${ }^{[a]}$, Elsa Midori Shimazaki ${ }^{[b]^{*}}$

[a] Universidade Tecnológica Federal do Paraná, (UTFPR), Ponta Grossa, PR, Brasil

[b] Universidade Estadual de Maringá, (UEM), Maringá, PR, Brasil

* LVMV: Doutorando em Ensino de Ciência e Tecnologia, e-mail: Imamcaszviginheski@gmail.com JPA: Doutorando em Ensino de Ciência e Tecnologia, e-mail: joao@utfpr.edu.br SCRS: Doutora em Ciências dos Materiais, e-mail: sanirutz@gmail.com LAP: Doutor em Educação física, e-mail: lapilatti@utfpr.edu.br ACF: Doutor em Educação, e-mail: ancafra@gmail.com SEM: Doutora em Educação, e-mail: emshimazaki@uem.br 


\section{Resumo}

Este artigo teve como objetivo analisar produções técnicas da área de Matemática para o Ensino Fundamental, desenvolvidas no período de junho de 2009 a dezembro de 2013 no Mestrado Profissional em Ensino de Ciência e Tecnologia da Universidade Tecnológica Federal do Paraná - Câmpus Ponta Grossa, avaliando a viabilidade de adaptação dos produtos para o ensino de estudantes cegos. A pesquisa apresenta uma abordagem qualitativa para a análise dos dados, sendo utilizada como estratégia a pesquisa bibliográfica, com análise das dissertações defendidas. O programa possui dezenove trabalhos na área de Matemática, sendo seis produções voltadas para o Ensino Fundamental. A análise comparativa dos trabaIhos coletou as seguintes informações: procedimentos metodológicos, recursos materiais e processos avaliativos. As propostas de adaptações das produções para os estudantes cegos deram-se a partir do referencial teórico registrado neste estudo. Os resultados desta análise indicam que as produções técnicas podem ser desenvolvidas também com estudantes cegos, desde que realizadas as adaptações conforme as necessidades do aluno.

Palavras-chave: Produção técnica. Ensino de matemática. Adaptação de material. Cegueira.

\section{Abstract}

This paper analyzed technical productions in the area of Mathematics for Elementary School, which were developed from June 2009 to December 2013, during the Professional Masters in Teaching Science and Technology of the Federal Technological University of Paraná - Câmpus Ponta Grossa, considering the viability of adapting products for teaching blind students. The investigation presents a qualitative approach to data analysis, using the bibliographic research as a strategy, with analysis of dissertations. The program has nineteen works in the area of mathematics, being six productions headed for Elementary School. The comparative analysis of the collected productions has utilized the following information: methodological procedures, material resources and evaluation processes. The proposals for adaptations of productions for blind students came from the theoretical framework registered in the present study. The results of the analysis indicated that the production techniques can also be developed with blind students, since the adjustments according to the needs of the student are made. 
Keywords: Technical productions. Mathematics teaching. Material adaptation. Blindness.

\section{Resumen}

Este artículo pretende analizar producciones técnicas del área de Matemáticas para la Enseñanza Fundamental, desarrolladas en el período de junio de 2009 a diciembre de 2013 en la Maestría Profesional en la enseñanza de Ciencia y Tecnología de la Universidad Tecnológica Federal de Paraná - Campus Ponta Grossa, evaluando a viabilidad de adaptación de los productos para enseñanza de estudiantes ciegos. La pesquisa presenta un abordaje cualitativo para el análisis de los datos, siendo utilizada como estrategia la pesquisa bibliográfica, con análisis de las disertaciones defendidas. El programa posee diecinueve trabajos en el área de Matemáticas, siendo seis producciones dirigidas para la Enseñanza Fundamental. El análisis comparativo de los trabajos recogió las siguientes informaciones: procedimientos metodológicos, recursos materiales y procesos evaluativos. Las propuestas de adaptaciones de las producciones para los estudiantes ciegos ocurrieron a partir del referencial teórico registrado en este estudio. Los resultados de este análisis indican que las producciones técnicas pueden ser desarrolladas también con estudiantes ciegos, desde que realizadas las adaptaciones de acuerdo a las necesidades del alumno.

Palabras-clave: producción técnica. Enseñanza de matemáticas. Adaptación de materiales. ceguera.

\section{Introdução}

As discussões sobre a inclusão de pessoas com deficiência no ensino regular foram intensificadas a partir da década de 90 e, a partir da Declaração de Salamanca (SALAMANCA, 1994), foram definidas políticas, princípios e práticas, para assegurar uma educação de qualidade para todos e construir uma sociedade inclusiva. No Brasil, a Lei de Diretrizes e Bases da Educação Nacional — LDBEN 9394/96 (BRASIL, 1996) passou por alterações, dedicando um capítulo à Educação Especial. Estas alterações garantiram o atendimento educacional especializado, especialmente em escolas públicas, a todos os estudantes com deficiência. 
A Lei 9394/96 atribui aos sistemas de ensino a função de assegurar a estes estudantes currículos diferenciados, como a utilização de métodos, técnicas, e recursos educativos adaptados para atender às necessidades específicas da deficiência, além de prover professores capacitados para o ensino de pessoas especiais nas classes comuns, efetuando adaptações para a trajetória do aluno quando necessário.

Na Educação Básica a presença de estudantes com deficiência, entre eles os estudantes cegos, leva os professores a buscarem diferentes metodologias, processos de ensino apropriados, além de materiais adaptados para promover o acesso desses estudantes ao conhecimento científico, visto que uma das suas necessidades para frequentar o Ensino Regular refere-se às adaptações.

Dentre as diversas disciplinas ofertadas nos currículos, a Matemática é uma das que mais necessita de adaptações, principalmente para o ensino de estudantes cegos. Os professores da disciplina podem sentir dificuldades, uma vez que muitos não têm conhecimento em como lecionar a alunos com estas limitações.

Os mestrados profissionais valorizam a pesquisa aplicada e a inovação na aplicação profissional (MOREIRA, 2004), disponíveis para serem aplicadas na educação básica, cenário educacional no qual os estudantes cegos recebem sua formação acadêmica.

Com isso, as adaptações de tais produções podem auxiliar os professores de Matemática no ensino para estudantes cegos a contribuírem para a melhoria da qualidade de ensino a esses estudantes, assim como para a inclusão deles no processo de elaboração do conhecimento.

Dessa forma, este artigo tem como objetivo analisar produções técnicas desenvolvidas no Mestrado Profissional em Ensino de Ciência e Tecnologia da UTFPR - Câmpus Ponta Grossa, na área de ensino de Matemática voltado para o Ensino Fundamental, apresentando possibilidades de adaptação dessas produções, de forma a atender estudantes cegos.

Os documentos Parâmetros Curriculares Nacionais e o Projeto Escola Viva: Garantindo o Acesso e a Permanência de todos os Alunos na Escola, descrevem que existem dois tipos de adaptações possíveis no contexto 
escolar: as curriculares de grande porte, as quais dependem de autorização superior (outras instâncias) e as curriculares de pequeno porte, que são realizadas pelo professor, de modo a garantir que todos os alunos tenham acesso ao conhecimento (BRASIL, 1998; BRASIL, 2000).

Neste trabalho, consideram-se as adaptações curriculares de pequeno porte. Elas são realizadas de forma a organizar o trabalho pedagógico, como é o caso da organização didática, do espaço necessário para o desenvolvimento da ação, dos materiais usados para realização da atividade e da adaptação deles para os alunos, entre outros.

\section{Marco teórico}

O documento Parâmetros Curriculares Nacionais (PCN) Adaptações Curriculares (BRASIL) considera que o currículo se constitui pela identidade escolar, a sua organização, o funcionamento e o papel da escola. Aponta, também, que uma educação para todos se efetiva a partir da elaboração do currículo pensado de forma dinâmica, com possibilidades de ajustes na prática pedagógica de modo que atenda às necessidades de todos os estudantes.

Neste cenário é preciso avaliar as dificuldades enfrentadas por estudantes cegos, conhecer o tipo da deficiência visual existente, quais soluções estão disponíveis para a aprendizagem ocorrer, bem como analisar a necessidade de adaptar as disciplinas de maneira que beneficie o acesso ao conhecimento, independente da forma que ele ocorra.

A diversidade se apresenta na forma como as pessoas cegas obtêm as informações por meio desses sentidos. Sá, Campos e Silva (2007, p. 16) consideram que cada pessoa desenvolve processos particulares de codificação, formado imagens mentais. A habilidade para compreender, interpretar e assimilar a informação será ampliada de acordo com a pluralidade das experiências, a variedade e qualidade do material, a clareza, a simplicidade e o modo como o comportamento exploratório é estimulado e desenvolvido. 
Com isso, as adaptações curriculares, além de outras ações escolares, também precisam ser pensadas no coletivo, a partir do cotidiano escolar, considerando os valores, as necessidades e as capacidades de seus estudantes. Assim, para os PCN - Adaptações Curriculares (BRASIL, 1996), as adaptações curriculares constituem, pois, possibilidades educacionais de atuar frente às diferenças de aprendizagem dos alunos. [...] Não um novo currículo, mas um currículo dinâmico, alterável, passível de ampliação para que atendam realmente a todos os educandos.

Os documentos PCN - Adaptações Curriculares (BRASIL, 1998) e o documento Projeto Escola Viva relacionam dois tipos de adaptações curriculares: as de grande porte ou significativas e as de pequeno porte, também chamadas de adaptações não significativas. Apontam, também, que esses dois tipos de adaptações curriculares envolvem adaptações relacionadas à promoção de acesso ao currículo, aos conteúdos, objetivos e métodos de ensino, ao processo de avaliação e à temporalidade.

Em relação ao conteúdo, se destacam a priorização de unidades curriculares, objetivos a serem atingidos, sequência de conteúdo e eliminação de conteúdos secundários. Em relação aos procedimentos didáticos, é possível usar atividades complementares, modificar o nível de complexidade das atividades, realizar adaptações de materiais, assim como adequação do tempo da atividade. Nos processos avaliativos o professor pode fazer uso de diferentes procedimentos e instrumentos, adaptados conforme a necessidade e possibilidade de expressão do estudante

As adaptações curriculares de grande porte (BRASIL,1998; BRASIL, 2000) são determinadas por instâncias superiores, pois envolvem ações políticas, administrativas, financeiras, entre outras. As adaptações de pequeno porte podem ser realizadas pelo próprio professor uma vez que não dependem de permissões de instâncias superiores, de forma a promover a participação ativa do estudante com deficiência no processo de aprendizagem (BRASIL, 1998; BRASIL, 2000).

Em se tratando de estudantes cegos, as adaptações implicam um novo olhar metodológico, maneiras diferentes para ensinar e avaliar o processo de ensino e de aprendizagem, além de adaptações de recursos 
materiais, os quais constituem-se como recursos de apoio, promovendo alterações nos níveis de abstração, podendo ser auditivos, gráficos, materiais manipulativos, entre outros (BRASIL, 2000).

Contribuindo com a discussão, o Documento Projeto Escola Viva (BRASIL, 2000) destaca que as adaptações curriculares consistem em procurar estratégias que melhor respondam às características e necessidades dos estudantes cegos. Para isso, o professor necessita modificar os procedimentos de ensino, introduzir atividades alternativas e complementares às planejadas. O documento considera também entre as competências do professor para a inclusão do estudante cego, a necessidade de se estabelecer entre eles o melhor nível de comunicação e de interação, explicar oralmente suas ações em sala de aula, criando condições para a sua participação ativa em todas as atividades propostas, assim como a utilização de recursos apropriados.

Para Sá, Campos e Silva (2007) os recursos básicos utilizados pelos estudantes cegos são o sistema Braille, como código que possibilita o acesso à leitura e a escrita; o soroban, que permite ao estudante cego o desenvolvimento de operações matemáticas, e softwares como o DOSVOX, o JAWS, o NVDA e outros que permitem navegar na internet, utilizar o correio eletrônico, o processamento de textos, planilhas e outros aplicativos.

Muitos dos materiais utilizados por estudantes sem deficiência visual podem ser utilizados por estudantes cegos, sendo desnecessárias adaptações, como é o caso do material dourado, da escala Cuisenaire, dos sólidos geométricos, entre outros.

Porém, alguns recursos para serem utilizados necessitam de adaptações, como é o caso dos instrumentos de medida, que devem ter graduação tátil. Reily (2004) relaciona alguns materiais que permitem a transformação de traços em relevos, como giz de cera sobre tela de náilon, tintas relevo, bolinhas de plastilina, figuras em material emborrachado com texturas (EVA), barbantes, entre outros.

Outros recursos podem ser utilizados para facilitar o acesso do estudante cego às informações, como maquetes e mapas adaptados adequadamente. O documento Saberes e Práticas da Inclusão (BRASIL, 2000) 
discorre sobre a criação de elementos táteis de forma criteriosa e com explicações objetivas. Uma adaptação com muitos detalhes pode dificultar a percepção de aspectos significativos. Assim, as texturas escolhidas e os tamanhos devem ser adequados para que a adaptação proporcione ao estudante o significado esperado.

\section{Metodologia}

Na organização do estudo foram adotados os seguintes passos: i) identificação e acesso aos trabalhos que contemplassem o ensino de Matemática nos anos finais do Ensino Fundamental e Ensino Médio; ii) definição das características a serem avaliadas; iii) análise das características desenvolvidas; iv) verificação da viabilidade da adaptação dos produtos para alunos cegos.

Para identificar os trabalhos foi consultada a página do programa de Pós-Graduação em Ensino de Ciência e Tecnologia da UTFPR - Câmpus Ponta Grossa, a qual disponibiliza os dados dos trabalhos (título, autor, orientador, ano de defesa) e, também, o link para o arquivo do trabalho.

O programa apresenta nesse período o total de setenta e cinco (75) produções (das quais quatro (04) não estavam disponíveis na página do programa), sendo vinte (20) delas voltadas ao Ensino de Matemática, e das quais onze (11) foram desenvolvidas especificamente para os anos finais do Ensino Fundamental e Ensino Médio, que constituem o foco das análises.

Para realização da análise de cada produto, os dados obtidos foram categorizados em:

I. tipo da produção: analisar qual produto foi desenvolvido;

II. objetivos e conteúdo: ponderar qual o conteúdo que a produção trata;

III. procedimentos metodológicos: avaliar a estratégia utilizada pelo docente para o ensino dos conteúdos; 
IV. recursos materiais: verificar quais recursos são necessários para a efetivação do processo de ensino-aprendizagem;

V. procedimentos avaliativos: examinar quais instrumentos e abordagens são utilizados para verificar a apropriação do conteúdo pelos estudantes.

Para verificar as possibilidades de adaptações para o uso com estudantes cegos foram utilizadas as orientações sobre as adaptações de pequeno porte, nos quais os professores têm autonomia de realizar mudanças metodológicas para atendimento do conteúdo.

Ao final, faz-se uma discussão acerca dessas possibilidades, com base nas orientações contidas na Lei de Diretrizes e Bases da Educação (BRASIL, 2006), Sá, Campos e Silva (2007) e Reily (2004), realizando uma avaliação global com base nas características levantadas e sua aplicabilidade no ensino de Matemática para estudantes cegos.

\section{Resultados e discussão}

Nesta seção, são apresentadas as produções técnicas que foram selecionadas para esta análise, assim como as possibilidades de adaptação para a sua utilização com estudantes cegos.

Uma síntese das produções técnicas é apresentada em dois quadros, os quais apresentam os objetivos propostos no trabalho, os procedimentos metodológicos adotados para se chegar ao objetivo, quais materiais são usados para o desenvolvimento das atividades e que formas de avaliação são adequadas para o trabalho proposto.

O Quadro 1 faz apresenta os trabalhos desenvolvidos para os anos finais do Ensino Fundamental e o Quadro 2 refere-se às produções técnicas direcionadas ao Ensino Médio. 
Quadro 1 - Características analisadas nos trabalhos selecionados voltados para os anos finais do Ensino Fundamental

\begin{tabular}{|c|c|c|c|c|}
\hline $\begin{array}{l}\text { Título do } \\
\text { Trabalho }\end{array}$ & Objetivos & $\begin{array}{l}\text { Procedimentos } \\
\text { metodológicos }\end{array}$ & $\begin{array}{l}\text { Materiais } \\
\text { utilizados }\end{array}$ & $\begin{array}{l}\text { Formas de } \\
\text { avaliação }\end{array}$ \\
\hline $\begin{array}{l}\text { Caderno } \\
\text { pedagógico: } \\
\text { auxiliando } \\
\text { o processo } \\
\text { de ensino- } \\
\text { aprendizagem } \\
\text { da geometria } \\
\text { (Shirlo, 2009). }\end{array}$ & $\begin{array}{l}\text { Reconhecer, } \\
\text { definir e calcular } \\
\text { a área de figuras } \\
\text { geométricas } \\
\text { planas. }\end{array}$ & $\begin{array}{l}\text { Exposição do con- } \\
\text { teúdo conforme } \\
\text { as orientações } \\
\text { das tendências } \\
\text { para o ensino } \\
\text { de Matemática } \\
\text { (Formalismo } \\
\text { Clássico, } \\
\text { Formalismo } \\
\text { Moderno e } \\
\text { Resolução de } \\
\text { Problemas). }\end{array}$ & $\begin{array}{l}\text { Livro didático } \\
\text { Embalagens } \\
\text { Cartolina }\end{array}$ & $\begin{array}{l}\text { Observação na } \\
\text { pontualidade } \\
\text { e do } \\
\text { desenvolvimento } \\
\text { das tarefas, } \\
\text { bem como o } \\
\text { desempenho } \\
\text { do estudante } \\
\text { ao longo das } \\
\text { atividades. }\end{array}$ \\
\hline $\begin{array}{l}\text { Caderno } \\
\text { pedagógico para } \\
\text { a elaboração } \\
\text { e aplicação de } \\
\text { projetos de } \\
\text { trabalho: uma } \\
\text { construção } \\
\text { para o ensino e } \\
\text { aprendizagem } \\
\text { (Oliveira, 2012). }\end{array}$ & $\begin{array}{l}\text { Oferecer } \\
\text { estratégias de } \\
\text { organização de } \\
\text { conhecimentos } \\
\text { escolares } \\
\text { em relação } \\
\text { ao ensino e } \\
\text { aprendizagem, } \\
\text { a partir de } \\
\text { projetos de } \\
\text { trabalho. }\end{array}$ & $\begin{array}{l}\text { Aplicação de } \\
\text { questionário } \\
\text { aos estudantes; } \\
\text { apresentação de } \\
\text { documentários; } \\
\text { realização de } \\
\text { pesquisa sobre o } \\
\text { tema estudado, } \\
\text { análise de } \\
\text { embalagens } \\
\text { contextualizada } \\
\text { com a geometria. }\end{array}$ & $\begin{array}{l}\text { Questionário } \\
\text { Filmes } \\
\text { Panfletos } \\
\text { Portfólio } \\
\text { Internet } \\
\text { Tabelas } \\
\text { Gráficos }\end{array}$ & $\begin{array}{l}\text { Utilização de } \\
\text { diferentes } \\
\text { instrumentos } \\
\text { avaliativos } \\
\text { para verificar } \\
\text { o raciocínio } \\
\text { nos cálculos, } \\
\text { elaboração e } \\
\text { apresentação da } \\
\text { pesquisa. }\end{array}$ \\
\hline $\begin{array}{l}\text { Manual didático } \\
\text { para aplicação } \\
\text { da oficina: } \\
\text { a bandeira } \\
\text { nacional na } \\
\text { medida certa } \\
\text { (Szumski, 2011). }\end{array}$ & $\begin{array}{l}\text { Apresentar } \\
\text { oficinas } \\
\text { contextualizadas } \\
\text { para o ensino } \\
\text { de geometria, } \\
\text { usando a } \\
\text { Bandeira } \\
\text { Nacional. }\end{array}$ & $\begin{array}{l}\text { Pesquisa em } \\
\text { grupos sobre } \\
\text { a história da } \\
\text { Bandeira Nacional; } \\
\text { confecção da } \\
\text { Bandeira Nacional; } \\
\text { ampliação da } \\
\text { bandeira para a } \\
\text { construção das } \\
\text { estrelas conforme } \\
\text { a Lei } \\
\text { n. 5.700/71. }\end{array}$ & $\begin{array}{l}\text { TV Pen drive } \\
\text { Imagens das } \\
\text { bandeiras } \\
\text { que o Brasil } \\
\text { teve } \\
\text { Instrumentos } \\
\text { de medida }\end{array}$ & $\begin{array}{l}\text { Avaliação } \\
\text { contínua e } \\
\text { diagnóstica, } \\
\text { por meio da } \\
\text { observação } \\
\text { dos estudantes } \\
\text { durante a } \\
\text { construção, as } \\
\text { discussões e } \\
\text { pesquisas. }\end{array}$ \\
\hline $\begin{array}{l}\text { O ensino de } \\
\text { potências e suas } \\
\text { propriedades: } \\
\text { um enfoque } \\
\text { à luz das } \\
\text { neurociências } \\
\text { (Pizyblski, 2011). }\end{array}$ & $\begin{array}{l}\text { Revisar o } \\
\text { conteúdo } \\
\text { matemático } \\
\text { potências e suas } \\
\text { propriedades. }\end{array}$ & $\begin{array}{l}\text { Aplicação de } \\
\text { uma revista em } \\
\text { quadrinhos após } \\
\text { o ensino do } \\
\text { conteúdo. }\end{array}$ & $\begin{array}{l}\text { Revista em } \\
\text { quadrinhos }\end{array}$ & $\begin{array}{l}\text { Avaliação } \\
\text { com base na } \\
\text { percepção dos } \\
\text { estudantes sobre } \\
\text { o material. }\end{array}$ \\
\hline
\end{tabular}

(Continua) 
(Conclusão)

\begin{tabular}{|c|c|c|c|c|}
\hline $\begin{array}{l}\text { Título do } \\
\text { Trabalho }\end{array}$ & Objetivos & $\begin{array}{l}\text { Procedimentos } \\
\text { metodológicos }\end{array}$ & $\begin{array}{l}\text { Materiais } \\
\text { utilizados }\end{array}$ & $\begin{array}{l}\text { Formas de } \\
\text { avaliação }\end{array}$ \\
\hline $\begin{array}{l}\text { Sequência } \\
\text { de ensino } \\
\text { contemplando } \\
\text { a estatística } \\
\text { nos anos finais } \\
\text { do ensino } \\
\text { fundamental } \\
\text { segundo os } \\
\text { pressupostos da } \\
\text { contextualização } \\
\text { (Walichinski, } \\
\text { 2012). }\end{array}$ & $\begin{array}{l}\text { Apresentar } \\
\text { uma sequência } \\
\text { de ensino para } \\
\text { os conceitos } \\
\text { básicos de } \\
\text { estatística. }\end{array}$ & $\begin{array}{l}\text { Aula expositiva } \\
\text { com apresentação } \\
\text { de pesquisa } \\
\text { estatística; técnicas } \\
\text { de coleta de dados; } \\
\text { organização de } \\
\text { dados em tabelas } \\
\text { e elaboração de } \\
\text { gráficos. }\end{array}$ & $\begin{array}{l}\text { Material } \\
\text { impresso } \\
\text { Textos } \\
\text { informativos } \\
\text { Gráficos } \\
\text { Tabelas } \\
\text { TV Pendrive } \\
\text { Estadiômetro } \\
\text { Balança de } \\
\text { pressão } \\
\text { Calculadora } \\
\text { Instrumentos } \\
\text { de medida }\end{array}$ & $\begin{array}{l}\text { Análise das } \\
\text { produções dos } \\
\text { estudantes. }\end{array}$ \\
\hline $\begin{array}{l}\text { Uma proposta } \\
\text { de ensino de } \\
\text { estatística } \\
\text { para um 6o } \\
\text { ano do ensino } \\
\text { fundamental em } \\
\text { uma escola do } \\
\text { campo (Pereira, } \\
\text { 2013). }\end{array}$ & $\begin{array}{l}\text { Disponibilizar } \\
\text { uma sequência } \\
\text { de ensino } \\
\text { de conceitos } \\
\text { básicos de } \\
\text { estatística. }\end{array}$ & $\begin{array}{l}\text { Coleta de dados; } \\
\text { apresentação } \\
\text { dos conceitos } \\
\text { estatísticos } \\
\text { vinculados com a } \\
\text { coleta realizada; } \\
\text { organização das } \\
\text { informações } \\
\text { e elaboração } \\
\text { de gráficos; } \\
\text { interpretação dos } \\
\text { dados. }\end{array}$ & $\begin{array}{l}\text { Questionário } \\
\text { Gráficos } \\
\text { Tabelas } \\
\text { Calculadora }\end{array}$ & $\begin{array}{l}\text { A autora não } \\
\text { aborda sobre } \\
\text { procedimentos } \\
\text { avaliativos. }\end{array}$ \\
\hline
\end{tabular}

Fonte: Elaborado pelos autores.

Quadro 2 - Características analisadas nos trabalhos selecionados voltados para o Ensino Médio

\begin{tabular}{|c|c|c|c|c|}
\hline $\begin{array}{l}\text { Título do } \\
\text { Trabalho }\end{array}$ & Objetivos & $\begin{array}{l}\text { Procedimentos } \\
\text { metodológicos }\end{array}$ & $\begin{array}{l}\text { Materiais } \\
\text { utilizados }\end{array}$ & $\begin{array}{l}\text { Formas de } \\
\text { avaliação }\end{array}$ \\
\hline \multirow[t]{2}{*}{$\begin{array}{l}\text { Caderno } \\
\text { pedagógico } \\
\text { para a } \\
\text { aplicação } \\
\text { da oficina } \\
\text { conhecendo } \\
\text { a geometria } \\
\text { fractal } \\
\text { (Nascimento, } \\
\text { 2012). }\end{array}$} & $\begin{array}{l}\text { Apresentar } \\
\text { referencial } \\
\text { teórico e } \\
\text { atividades sobre } \\
\text { geometria } \\
\text { fractal. }\end{array}$ & $\begin{array}{l}\text { Discussões sobre } \\
\text { geometria fractal; } \\
\text { identificação } \\
\text { de formas } \\
\text { geométricas } \\
\text { no cotidiano; } \\
\text { construção de } \\
\text { fractais; utilização } \\
\text { de software para } \\
\text { visualização e } \\
\text { exploração de } \\
\text { fractais. }\end{array}$ & $\begin{array}{l}\text { Quebra cabeça } \\
\text { Figuras } \\
\text { Vídeos } \\
\text { Slides } \\
\text { Instrumentos de } \\
\text { medida }\end{array}$ & $\begin{array}{l}\text { Observação } \\
\text { contínua pelo } \\
\text { professor nos } \\
\text { diferentes } \\
\text { momentos das } \\
\text { atividades } \\
\text { Exposição } \\
\text { dos fractais } \\
\text { elaborados pelos } \\
\text { estudantes. }\end{array}$ \\
\hline & & & & (Continua) \\
\hline
\end{tabular}




\begin{tabular}{|c|c|c|c|c|}
\hline $\begin{array}{l}\text { Título do } \\
\text { Trabalho }\end{array}$ & Objetivos & $\begin{array}{l}\text { Procedimentos } \\
\text { metodológicos }\end{array}$ & $\begin{array}{l}\text { Materiais } \\
\text { utilizados }\end{array}$ & $\begin{array}{l}\text { Formas de } \\
\text { avaliação }\end{array}$ \\
\hline $\begin{array}{l}\text { Guia } \\
\text { pedagógico } \\
\text { de atividades } \\
\text { para o ensino } \\
\text { de geometria } \\
\text { com a } \\
\text { utilização de } \\
\text { caleidociclos } \\
\text { (Sanches, }\end{array}$ & $\begin{array}{l}\text { Desenvolver } \\
\text { atividades para } \\
\text { o ensino e } \\
\text { aprendizagem } \\
\text { de geometria. }\end{array}$ & $\begin{array}{l}\text { Entrevista } \\
\text { diagnóstica; } \\
\text { definição de } \\
\text { conceitos; } \\
\text { leitura de textos } \\
\text { informativos sobre } \\
\text { caleidociclos; } \\
\text { construção de } \\
\text { caleidociclos. }\end{array}$ & $\begin{array}{l}\text { Projetor } \\
\text { multimídia } \\
\text { Vídeos } \\
\text { Computador } \\
\text { Tangran } \\
\text { Geoplano }\end{array}$ & $\begin{array}{l}\text { Avaliação } \\
\text { diagnóstica. }\end{array}$ \\
\hline
\end{tabular}
2012).

\begin{tabular}{|c|c|c|c|c|}
\hline $\begin{array}{l}\text { Manual } \\
\text { didático para } \\
\text { o professor: } \\
\text { atividades } \\
\text { com o octave } \\
\text { para o ensino } \\
\text { de funções } \\
\text { de primeiro } \\
\text { e segundo } \\
\text { grau e suas } \\
\text { relações no } \\
\text { movimento } \\
\text { retilíneo } \\
\text { (Barbosa, } \\
\text { 2012). }\end{array}$ & $\begin{array}{l}\text { Ensinar funções } \\
\text { do primeiro } \\
\text { e segundo } \\
\text { grau e suas } \\
\text { relações com } \\
\text { o movimento } \\
\text { retilíneo. }\end{array}$ & $\begin{array}{l}\text { Aplicação de } \\
\text { questionário sobre } \\
\text { conhecimentos } \\
\text { prévios; aulas } \\
\text { expositivas sobre } \\
\text { apresentação } \\
\text { e exploração } \\
\text { dos comandos } \\
\text { do software } \\
\text { Octave; estudo } \\
\text { das funções } \\
\text { do primeiro e } \\
\text { segundo grau; } \\
\text { contextualização } \\
\text { com movimento } \\
\text { retilíneo uniforme } \\
\text { e variado; } \\
\text { plotagem de } \\
\text { gráficos. }\end{array}$ & Software Octave & $\begin{array}{l}\text { O autor não } \\
\text { aborda sobre } \\
\text { procedimentos } \\
\text { avaliativos. }\end{array}$ \\
\hline $\begin{array}{l}\text { O ensino } \\
\text { de arte e } \\
\text { matemática: } \\
\text { abordagens } \\
\text { geométricas } \\
\text { (Semmer, } \\
\text { 2013). }\end{array}$ & $\begin{array}{l}\text { Auxiliar } \\
\text { professores de } \\
\text { Matemática } \\
\text { no ensino de } \\
\text { geometria não } \\
\text { euclidiana e } \\
\text { professores } \\
\text { de arte na } \\
\text { aplicação de } \\
\text { leitura de } \\
\text { imagens de } \\
\text { anamorfoses. }\end{array}$ & $\begin{array}{l}\text { Estudos e } \\
\text { construção de } \\
\text { imagens com } \\
\text { perspectiva e } \\
\text { anamorfose, } \\
\text { contextualizadas } \\
\text { com o cotidiano do } \\
\text { aluno; Aplicação } \\
\text { da técnica Washi } \\
\text { utilizando a } \\
\text { geometria em } \\
\text { superfícies ovais e } \\
\text { esféricas. }\end{array}$ & $\begin{array}{l}\text { Filme } \\
\text { Imagens } \\
\text { Revistas } \\
\text { Máquina } \\
\text { fotográfica } \\
\text { Goniômetro } \\
\text { Software } \\
\text { Geogebra } \\
\text { Grades de } \\
\text { anamorfose } \\
\text { Tabelas }\end{array}$ & $\begin{array}{l}\text { Avaliação no } \\
\text { decorrer do } \\
\text { processo, } \\
\text { por meio da } \\
\text { observação } \\
\text { dos alunos nos } \\
\text { procedimentos, } \\
\text { respostas, } \\
\text { comentários. }\end{array}$ \\
\hline
\end{tabular}

(Continua) 
(Conclusão)

\begin{tabular}{|c|c|c|c|c|}
\hline $\begin{array}{l}\text { Título do } \\
\text { Trabalho }\end{array}$ & Objetivos & $\begin{array}{l}\text { Procedimentos } \\
\text { metodológicos }\end{array}$ & $\begin{array}{l}\text { Materiais } \\
\text { utilizados }\end{array}$ & $\begin{array}{l}\text { Formas de } \\
\text { avaliação }\end{array}$ \\
\hline $\begin{array}{l}\text { Utilizando- } \\
\text { se da } \\
\text { modelagem } \\
\text { matemática } \\
\text { para explorar } \\
\text { conteúdos } \\
\text { da grade } \\
\text { curricular } \\
\text { através da } \\
\text { construção } \\
\text { de maquete } \\
\text { (Haliski, } \\
\text { 2010). }\end{array}$ & $\begin{array}{l}\text { Propiciar aulas } \\
\text { diferenciadas, } \\
\text { promovendo a } \\
\text { integração da } \\
\text { teoria com a } \\
\text { prática. }\end{array}$ & $\begin{array}{l}\text { Investigação } \\
\text { dos interesses } \\
\text { dos estudantes } \\
\text { por meio de } \\
\text { questionário; } \\
\text { estudos com } \\
\text { a planta baixa } \\
\text { do colégio; } \\
\text { interpretação } \\
\text { de escalas } \\
\text { e conversão } \\
\text { de medidas; } \\
\text { confecção de } \\
\text { maquete. }\end{array}$ & $\begin{array}{l}\text { Projetor } \\
\text { multimídia } \\
\text { Planta baixa } \\
\text { Instrumentos de } \\
\text { medida } \\
\text { Materiais para } \\
\text { confecção de } \\
\text { maquete }\end{array}$ & $\begin{array}{l}\text { A partir de } \\
\text { questionário, } \\
\text { entrevista e } \\
\text { observações no } \\
\text { decorrer das } \\
\text { atividades. }\end{array}$ \\
\hline
\end{tabular}

Fonte: Elaborado pelos autores.

Dentre os trabalhos analisados, encontram-se uma revista em quadrinhos, três cadernos pedagógicos, dois produtos que fornecem uma sequência de ensino para áreas específicas, três são manuais didáticos, um guia pedagógico e um texto de apoio. Dentre os conteúdos abordados, um dos trabalhos engloba o estudo de potências, um aborda funções, seis desenvolvem conceitos de geometria, dois enfocam conteúdos de estatística e um promove a articulação entre os conteúdos números e álgebra, grandezas e medidas, tratamento da informação e geometria.

De uma forma geral, pode-se verificar que a abordagem metodológica proposta nas produções técnicas permite a participação ativa de qualquer estudante. Os estudantes cegos também podem participar do processo de aprendizagem, sendo necessário o professor realizar adaptações adequadas dos materiais, quando possível, segundo a necessidade do aluno em particular.

As produções técnicas desenvolvidas por Haliski (2010), Szumski (2011), Barbosa (2012), Nascimento (2012), Oliveira (2012), Sanches (2012) Walichinski (2012), Semmer (2013) e Pereira (2013), descrevem o encaminhamento metodológico detalhadamente em etapas de ensino ou planos de aula. Na maioria dessas etapas ou planos é possível 
incluir a participação do estudante cego, sendo necessário o professor desenvolver adaptações adequadas dos materiais voltadas para utilização por estes estudantes.

Um ponto importante que precisa ser considerado para utilização por estudantes cegos de cada produção técnica analisada, diz respeito ao tempo destinado para a realização das atividades. Com base nos procedimentos adotados em cada uma delas, nos objetivos propostos e nas formas de avaliação, além do destacado no referencial teórico sobre respeito da necessidade de adaptação curricular e procedimental, certamente os estudantes cegos precisarão de um tempo maior que os demais alunos para finalizar cada atividade proposta. Assim, o professor precisa adequar a atividade e o tempo, para a obtenção de um resultado esperado.

Algumas produções utilizam em suas atividades o desenho, como a Bandeira Nacional e anamorfoses (SZUMSKI, 2011; SEMMER, 2013), a planificação de embalagens, construção de sólidos geométricos e maquetes (SHIRLO, 2009; HALINSKI, 2010; OLIVEIRA, 2012; SANCHES, 2012), além da construção de gráficos e tabelas (WALICHINSKI, 2012; OLIVEIRA, 2012; PEREIRA, 2013). Estas atividades e outras que possam ser percebidas pelo professor no desenvolvimento do trabalho com estudantes cegos, dependem, além do material adequado, de uma orientação constante do professor ou de colegas para a realização das atividades por estes estudantes, uma vez que as mesmas necessitam da utilização da visão.

Com relação aos recursos e materiais necessários para utilizar o produto, se destacam nas diferentes produções técnicas, materiais impressos (jornais, revistas, gráficos, textos informativos), o uso da TV Pen drive ou projetores de multimídia e da internet, além de filmes (documentários) relativos ao assunto tratado.

Sá, Campos e Silva (2007) orientam para o uso de recursos visuais com estudantes cegos, como é o caso da exposição do conteúdo em slides na TV Pen drive ou projetor multimídia, recurso utilizado pelas produções técnicas de Haliski (2010), Szumski (2011) e de Walichinski (2012), e vídeos, utilizados por Oliveira (2012), Sanches (2012) e Semmer (2013); a adaptação é feita por meio da descrição detalhada das imagens. 
A descrição é indicada até mesmo para filmes dublados. As autoras recomendam a elaboração de um resumo para esse aluno, em paralelo à apresentação, que virá facilitar a compreensão daquilo que está sendo apresentado. Importante frisar que a riqueza de detalhes escritas deve ser compatível com o que está sendo apresentado aos demais estudantes.

Para o desenvolvimento de pesquisa utilizando a internet, conforme abordado pelo trabalho de Oliveira (2012), se faz necessária a utilização de softwares que permitam a navegação na internet por usuários cegos. Dentre eles, destaca-se o DOS VOX, o NVDA, o JAWS.

Algumas produções técnicas fazem uso de softwares, como o Geogebra, proposto por Semmer (2013) e o Octave, utilizado na produção de Barbosa (2012). Não é possível avaliar, apenas pelo referencial teórico, a possibilidade de utilização deles pelos estudantes cegos, da mesma forma como vem sendo realizada as análises das demais produções. Fazse necessário verificar se os programas utilizados pelos estudantes cegos citados anteriormente conseguem fazer a leitura de tais softwares, possibilitando o acesso também por estes estudantes.

Para a utilização de livros didáticos, pesquisas em revistas, jornais, entre outros materiais impressos, conforme indicam as produções de Shirlo (2009), Pizyblski (2011), Oliveira (2012), Walichinski (2012) e Semmer (2013), é necessária, para o estudante cego, a adaptação dos mesmos no código Braille ou então, o auxílio de uma pessoa que realize a leitura dos textos.

A revista em quadrinhos proposta por Pizyblski (2011) pode ser adaptada para os estudantes cegos da mesma forma como a autora Silva (2013) o fez. Ela desenvolveu uma história em quadrinhos sobre o Teorema de Tales, adaptada para estudantes cegos. Os textos da história foram transcritos para a escrita em Braille e os desenhos, adaptados em relevo, mantendo os aspectos dos desenhos à tinta. Os relevos foram criados com a utilização de uma carretilha de costura sobre uma placa de borracha.

A adaptação de histórias em quadrinhos depende, no entanto, de alguns cuidados, principalmente no que diz respeito aos detalhes dos desenhos, porque a percepção tátil difere da percepção visual. Sá, Campos 
e Silva (2007) orientam que o relevo deve ser proporcionado pela utilização de diferentes texturas, resistentes ao tato, para que o estudante cego possa distinguir as partes que compõe o todo. Aponta-se como outra possibilidade para adaptar a história em quadrinhos a elaboração dos personagens como bonecos tridimensionais. Essa adaptação, por ser mais elaborada que a adaptação em relevo torna-se mais trabalhosa e demorada; porém, a leitura tátil pode perceber e identificar maiores detalhes.

A adaptação de imagens e figuras, que deverá ser realizada em produções como as de Szumski (2011), Nascimento (2012), Oliveira (2012) e Semmer (2013), pode se dar por intermédio da aplicação de relevo com diferentes texturas, assim como pela descrição do material, de forma escrita ou oral. Quando se opta pela descrição, faz-se necessário o professor apresentar com precisão os detalhes, por meio de um texto, com o objetivo de proporcionar informações complementares, que podem não ser percebidas pelo tato (REILY, 2004). Desta forma, será possível realizar a adaptação dessas produções para a utilização com estudantes cegos.

Para as atividades que solicitam dos estudantes a aferição de medidas (HALINSKI, 2010; SZUMSKI, 2011; NASCIMENTO, 2012; SANCHES, 2012; WALICHINSKI, 2012), os instrumentos que serão utilizados pelo estudante cego, como a régua, o compasso, o esquadro e outros, necessitam da adaptação por meio de marcação especial, como fissuras, pontos em relevo ou outras formas de adaptação que proporcionem saliência, realce e elevação na parte graduada do instrumento.

As produções de Shirlo (2009) e Oliveira (2012) fazem uso de embalagens como recursos materiais. Haliski (2010) propõe a construção de uma maquete e Sanches (2012), a construção de caleidociclos. Quando o encaminhamento metodológico sugere a construção de um objeto, com determinadas dimensões para resolver um problema, o estudante cego também pode construir o seu com o auxílio de colegas e do professor. No caso da produção técnica de Oliveira (2012), que faz uso de imagens da embalagem do medicamento, elas podem ser substituídas pela própria embalagem. 
Algumas atividades das produções técnicas de Shirlo (2009) e de Oliveira (2012) propõem a análise de figuras bi e tridimensionais, o cálculo da área e do volume do paralelepípedo, a partir do uso da planificação da embalagem, e a identificação dos vértices, das arestas, das faces. Para adaptação da atividade, é possível solicitar ao estudante cego planificar a sua embalagem sobre um Geoplano, marcando as arestas com elásticos. Outra possibilidade é fazer o desenho no papel vegetal. As arestas e as unidades de área são vincadas e as arestas perfuradas. Para o cálculo do volume, o estudante cego pode fazer uso das unidades cúbicas do Material Dourado, conforme pode ser visualizado na Figura 1.

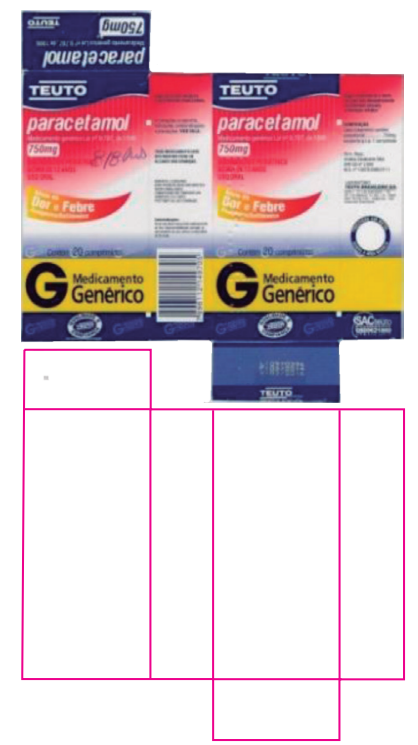

Figura 1 - Adaptação de planificação de embalagem de medicamento Fonte: Elaborado pelos autores.

As produções técnicas de Szumski (2011), Oliveira (2012), Walichinski (2012), Pereira (2013) e Semmer (2013) fazem uso de gráficos e tabelas. A adaptação dos gráficos pode ser realizada em relevo, 
utilizando texturas proporcionadas por diferentes materiais como papéis, tecidos ou EVA. Também é possível a adaptação por meio da descrição oral ou escrita do conteúdo do gráfico ou da tabela.

A questão de vestibular (UNICENTRO, 2013, p. 30), conforme a Figura 2 a seguir, exemplifica a adaptação de um gráfico por meio da descrição:

Na figura, a seguir, são dados os pontos $\mathrm{A}(-2,0), \mathrm{B}(2,0)$ e $\mathrm{O}(0,0)$.

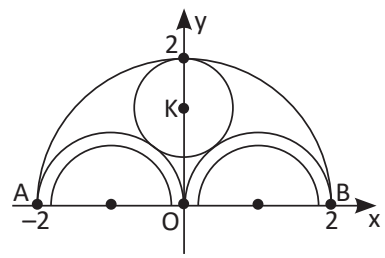

Figura 2 - Questão de vestibular

Fonte: Unicentro, 2013.

A adaptação descritiva do gráfico deu-se da seguinte forma (UNICENTRO, 2013):

Essa figura encontra-se no plano cartesiano, entre o primeiro e o segundo quadrantes, e mostra 5 semicircunferências e 1 circunferência que tangencia 3 dessas semicircunferências. Uma das semicircunferências é maior, com centro na origem $O$, diâmetro $A B$ no eixo $x$ e raio $\mathrm{OP}$ no eixo y. As coordenadas do ponto $\mathrm{A}$ são -2 e 0 ; do ponto $\mathrm{B}, 2 \mathrm{e}$ 0 ; do ponto $\mathrm{O}, 0$ e 0 . No interior da semicircunferência maior, há duas semicircunferências menores, uma, ä esquerda do eixo y, de diâmetro $\mathrm{AO}$, e outra à direita, de diâmetro $\mathrm{OB}$. No interior da semicircunferência de diâmetro $\mathrm{AO}$, há outra semicircunferência de mesmo centro e de diâmetro $\mathrm{CE}$. No interior da semicircunferência de diâmetro $\mathrm{OB}$, há uma semicircunferência de mesmo centro e de diâmetro FD. A circunferência com centro no eixo $\mathrm{y}$, no ponto $\mathrm{K}$, tangencia a semicircunferência maior no ponto com coordenadas 0 e 2 e as semicircunferências de diâmetros $\mathrm{AO}$ e $\mathrm{OB}$ em pontos desconhecidos. 
Para fazer uso desse tipo de adaptação, o estudante cego precisa ter conhecimento sobre os conceitos que estão sendo descritos, de forma que consiga elaborar mentalmente a imagem e, a partir disso, resolver a atividade. Daí a importância de proporcionar a este estudante mais de uma forma de adaptação, estabelecendo um comparativo entre as que forem utilizadas, uma vez que ele, assim como os demais estudantes, passará por processos seletivos, como vestibulares, concursos e exames que também utilizam essa forma de adaptação.

A Figura 3 ilustra um exemplo de adaptação de um gráfico para este estudante, utilizando escrita em braile para representar os eixos, e a colagem de materiais de EVA com diferentes texturas, para representar as barras do gráfico. Conforme o estudo, a simplificação do gráfico pode facilitar a leitura tátil. Com o auxílio de colegas e de professores, o estudante cego também pode elaborar um gráfico.

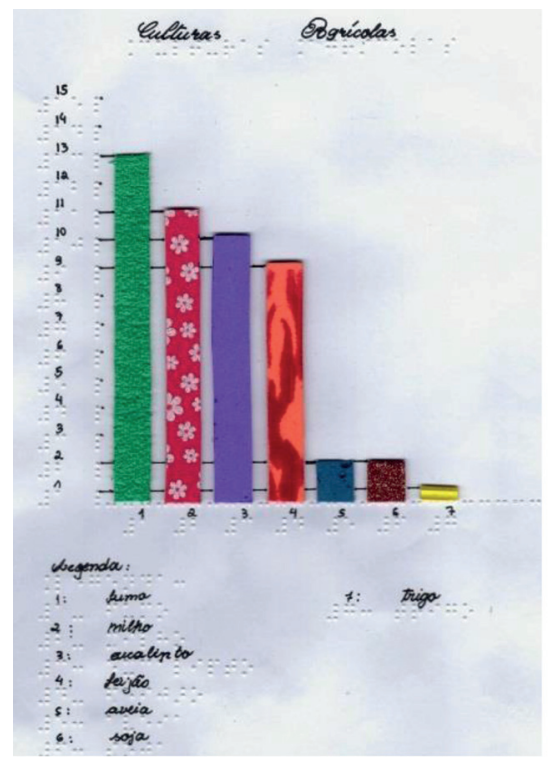

Figura 3 - Adaptação de gráfico em relevo

Fonte: Elaborado pelos autores. 
O estudante cego também tem a possibilidade de organizar os dados em tabelas, no Excel, conforme o leitor de tela que ele tiver disponível, ou ainda, fazendo uso da máquina Braille, com o auxílio de colegas ou de professores. A Figura 4 apresenta um exemplo de uma tabela adaptada em Braille:

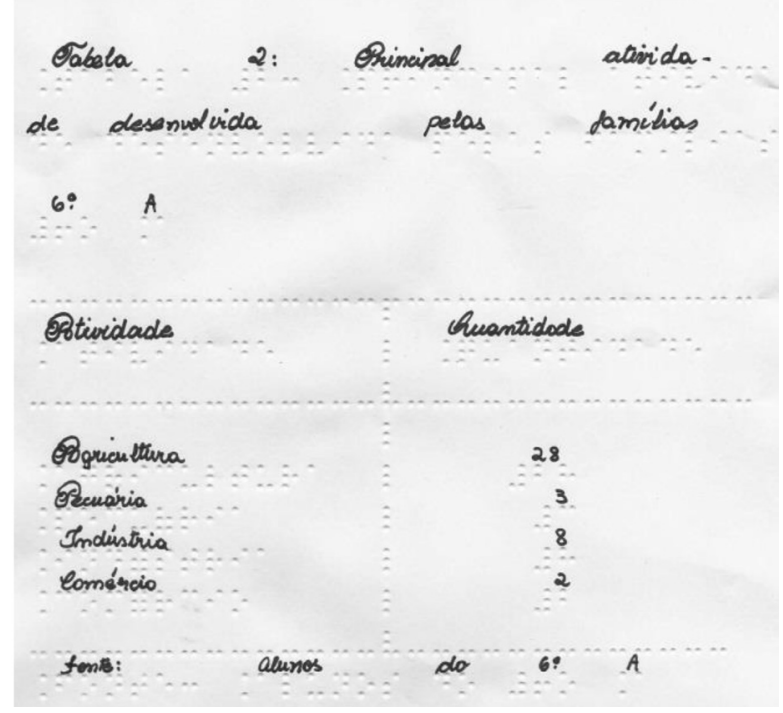

Figura 4 - Tabela em Braille

Fonte: Elaborado pelos autores.

Para os cálculos matemáticos, pode ser utilizado o soroban, porém, em algumas produções que fazem uso de cálculos estatísticos, a utilização de uma calculadora sonora facilitaria o trabalho para o estudante cego.

Destacam-se, entre as produções analisadas, algumas que fazem uso de materiais mais complexos para a adaptação, como o caso de uso de imagens com anamorfoses, proposto pela produção de Semmer (2013). É possível que uma adaptação para a leitura tátil não proporcione para os estudantes cegos o mesmo efeito que é proporcionado visualmente, ou 
seja, há possibilidade de uma distorção da imagem. Entretanto, isso não deve ser motivo para o professor eliminar as atividades propostas para este estudante. É pertinente que ele escolha imagens mais simples, com poucos detalhes, para realizar a adaptação. A Figura 5 retrata a adaptação de uma anamorfose. Os modelos confeccionados em EVA com textura não são fixos, de forma a possibilitar ao estudante cego a sobreposição deles nas malhas adaptadas em relevo e perceber tatilmente a alteração sofrida conforme a perspectiva trabalhada:

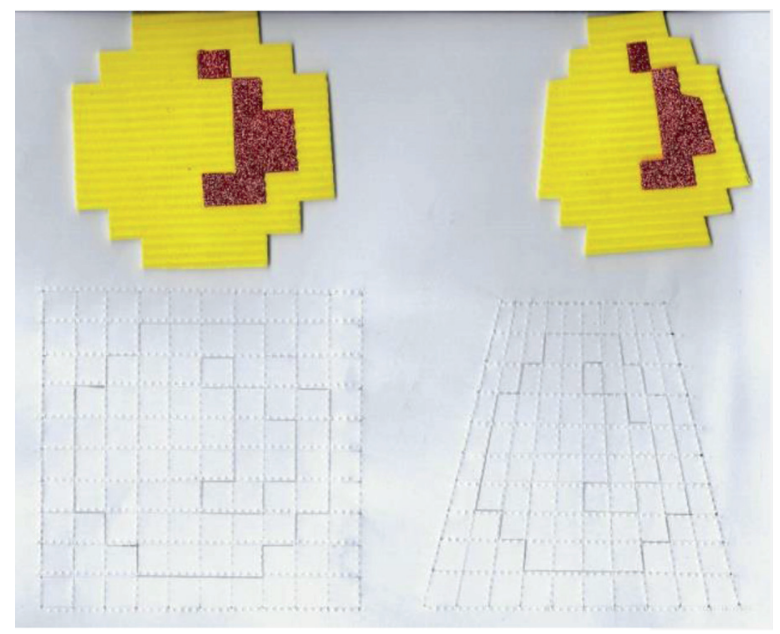

Figura 5 - Adaptação de grades de anamorfose

Fonte: Elaborado pelos autores.

Desta mesma forma, observa-se a produção técnica desenvolvida por Nascimento (2012), sobre geometria fractal. Apontam-se alguns questionamentos sobre as adaptações possíveis para a aplicação com estudantes cegos: segundo a autora, é possível perceber, imaginar o infinito a partir de modelos de fractais, por meio da visão. Talvez os professores possam se questionar sobre como proporcionar a percepção de infinito ao estudante cego, fazendo uso do tato. As representações das formas 
fractais por meio de gravuras, fotografias e outras apresentam limites, porém, proporcionam, a partir da imaginação, a percepção do infinito. $\mathrm{Da}$ mesma forma, adaptações táteis também serão limitadas e o estudante cego deverá ser orientado pelo professor a imaginar, a partir do concreto, a possibilidade do infinito. Dessa maneira, é possível trabalhar com imagens adaptadas em relevo, como as utilizadas por Nascimento (2012), o triângulo e o tapete de Sierpinski, a Curva de Koch, e outras, explicando para o estudante cego, que não é possível chegar ao fim de todas as representações. Para imagens mais complexas, pode-se fazer o uso de descrição, como representado na Figura 6 a seguir:

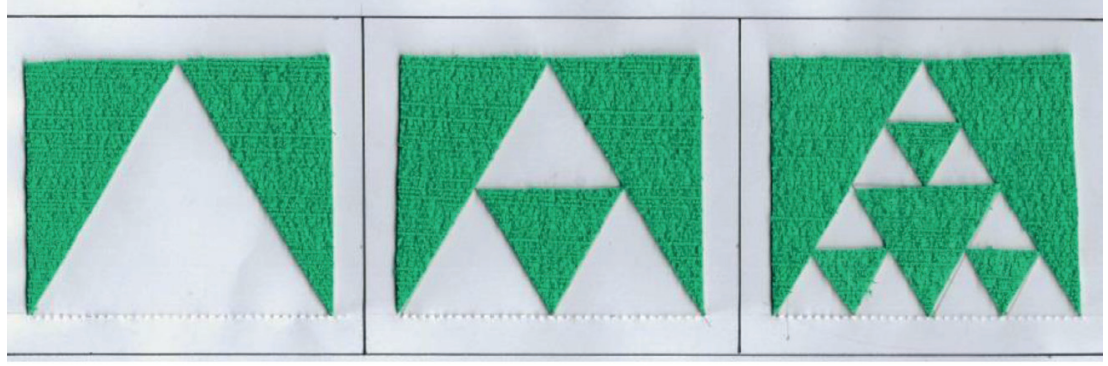

Figura 6 - Adaptação do Triângulo de Sierpinski Fonte: Elaborado pelos autores.

Em relação aos processos avaliativos, as estratégias adotadas nas produções vão desde apresentação de pesquisas realizadas, observações do professor na pontualidade e desenvolvimento das atividades, o desempenho dos estudantes, a análise das produções pelo professor, a participação nas discussões, o registro individual, entre outros.

O professor pode fazer uso dos mesmos instrumentos para os estudantes cegos, conforme abordados nas diferentes produções analisadas. Evidente que são necessárias adaptações para melhor aplicação da avaliação. No caso da utilização do instrumento de avaliação escrito, o mesmo pode ser transcrito para o código Braille ou ser realizado 
oralmente. Quando realizado em Braille, o número de questões pode ser diminuído, assim como ser considerada a necessidade de proporcionar ao estudante cego um tempo maior para a realização da avaliação.

A partir do que foi apresentado e discutido, levanta-se uma questão importante no ensino de Matemática para estudantes cegos: a necessidade do professor conhecer sobre aspectos característicos da deficiência visual, sobre o desenvolvimento das pessoas cegas, o diagnóstico, os recursos e alternativas disponíveis para o seu ensino, assim como a necessidade de desenvolver outras adaptações que favoreçam o acesso ao conhecimento, entre elas, as adaptações curriculares e dos processos de ensino, o que contribuirá para a participação ativa desses estudantes na elaboração do conhecimento.

O sistema de ensino oferece atendimento especializado a estudantes cegos por meio de serviços de apoio oferecidos pela Educação Especial. No entanto, a formação acadêmica deles é função do Ensino Regular e o professor de Matemática é o responsável em promover-lhes o acesso ao conhecimento sistematizado da disciplina. Contudo, o professor pode contar com a ajuda dos profissionais da Educação Especial para realizar as adaptações necessárias.

Outra questão refere-se à importância dos pesquisadores dos mestrados profissionais pensarem suas produções técnicas de forma inclusiva, procurando atender a toda demanda da educação básica, sejam estudantes com ou sem deficiências. As adaptações apontadas atendem não somente aos estudantes cegos, mas também aos estudantes que possam apresentar outro tipo de deficiência.

\section{Considerações finais}

O objetivo deste trabalho foi analisar as produções técnicas na área de Matemática, desenvolvidas em um programa de Mestrado Profissional, verificando a viabilidade em adaptar os produtos desenvolvidos para trabalhar com estudantes cegos. 
O corpus da pesquisa foi constituído por onze produções técnicas na área de Ensino de Matemática para Ensino Fundamental, defendidas no período de junho de 2009 a dezembro de 2013, do Mestrado Profissional em Ensino de Ciência e Tecnologia, do Programa de Pós-Graduação em Ensino de Ciência e Tecnologia da Universidade Tecnológica Federal do Paraná - Câmpus Ponta Grossa, Paraná, Brasil.

Foi possível observar que todas as produções analisadas podem ser desenvolvidas para estes estudantes, havendo necessidade de adaptações sendo, as mais comuns, a utilização de relevo e a escrita em Braille, as quais tornam o material acessível para estes alunos.

Nas adaptações metodológicas didáticas no ensino de Matemática para estudantes cegos, o professor pode lançar mão de recursos já disponíveis e utilizados pelos demais alunos, promover adaptações em materiais tornando-os acessíveis também para esses estudantes, além de idealizar e criar outros instrumentos, fazendo uso do seu conhecimento e de sua criatividade, promovendo com isso o acesso do estudante cego ao currículo.

As possibilidades de adaptações foram sugeridas a partir do referencial teórico adotado neste trabalho; salienta-se, entretanto, que uma adaptação realizada por uma pessoa que enxerga para um estudante cego pode não ser adequada para todos os estudantes cegos. Nisto é importante levar em consideração a opinião do estudante, assim como suas preferências, para que não ocorra desperdício de tempo, de material, e principalmente, que o recurso adaptado seja funcional e que permita alcançar aos objetivos propostos.

Ressalta-se também que um ensino, para ser inclusivo, não depende somente da utilização de recursos específicos, mas também de uma prática pedagógica inclusiva do professor. De nada vale o professor ter em mãos recursos materiais e tecnologias adequadas, se a sua prática for excludente.

Este estudo não se encerra aqui. Ele abre caminhos para outros estudos, principalmente no que diz respeito à realização das adaptações aqui sugeridas e de outras, que permitam a validação pelos estudantes cegos, na sala de aula, juntamente com os demais colegas. 


\section{Referências}

BARBOSA, T. H. N. Manual didático para o professor: atividades com o octave para o ensino de funções de primeiro e segundo graus e suas relações no movimento retilíneo. Tese (Mestrado em Ensino de Ciência e Tecnologia) - Universidade Tecnológica Federal do Paraná, Ponta Grossa, 2012. Disponível em: <http://repositorio.utfpr.edu.br/jspui/handle/1/1109>. Acesso em 30 jun. 2016.

BRASIL. Decreto-Lei 9.694 de 20 de Dezembro de 1996. Estabelece as diretrizes e bases da educação nacional. Disponível em: <http://portal.mec.gov.br/arquivos/pdf/ldb.pdf >. Acesso em: 30 jun. 2016.

BRASIL. Ministério da Educação. Parâmetros Curriculares Nacionais: adaptações curriculares. Brasília: MEC, Secretaria de Educação Fundamental. 1998.

BRASIL. Ministério da Educação. Projeto escola viva: garantindo o acesso e a permanência de todos os alunos na escola - alunos com necessidades educacionais especiais. Adaptações Curriculares de pequeno porte, 6. Brasília: MEC, SEF. 2000.

BRASIL. Ministério da Educação. Saberes e práticas da inclusão: desenvolvendo competências para o atendimento às necessidades educacionais especiais de alunos cegos e de alunos com baixa visão. Coordenação geral SEESP/MEC. Brasília: MEC, Secretaria de Educação Especial. 2006.

HALINSKI, A. M. Utilizando-se da modelagem matemática para explorar conteúdos da grade curricular através da construção de maquete. Tese (Mestrado em Ensino de Ciência e Tecnologia) - Universidade Tecnológica Federal do Paraná, Ponta Grossa, 2010. 2010. Disponível em: <http://ppgect.pg.utfpr.edu.br/site/wp-content/uploads/2013/09/9.zip >. Acesso em 30 jun. 2016.

MOREIRA, M. A. O mestrado (profissional) em ensino. Revista Brasileira de PósGraduação, v. 1, n. 1. 2004.

NASCIMENTO, M. Caderno pedagógico para aplicação da oficina conhecendo geometria fractal. Tese (Mestrado em Ensino de Ciência e Tecnologia) - Universidade Tecnológica do Paraná, Ponta Grossa, 2012. Disponível em: <http://ppgect.pg.utfpr.edu.br/ site/wp-content/uploads/2013/09/31.zip >. Acesso em 30 jun. 2016. 
OLIVEIRA, J. A. Caderno pedagógico para a elaboração e aplicação de projetos de trabalho: uma contribuição para o ensino e aprendizagem. Tese (Mestrado em Ensino de Ciência e Tecnologia) - Universidade Tecnológica do Paraná, Ponta Grossa, 2012. Disponível em: <http://ppgect.pg.utfpr.edu.br/site/wp-content/ uploads/2013/09/33.zip >. Acesso em: 30 jun. 2016.

PEREIRA, L. B. C. Uma proposta de ensino de Estatística para um 6. ano do ensino fundamental em uma escola do campo. Tese (Mestrado em Ensino de Ciência e Tecnologia) - Universidade Tecnológica do Paraná, Ponta Grossa, 2013. Disponível em: <http://ppgect.pg.utfpr.edu.br/site/wp-content/uploads/2013/09/75-Lucia na-Boemer-Cesar-Pereira.rar >. Acesso em: 30 jun. 2016.

PIZYBLSKI, L. M. O ensino de Potências e suas propriedades: um enfoque à luz das neuro-ciências. Dissertação (Mestrado em Ensino de Ciência e Tecnologia - Universidade Tecnológica Federal do Paraná, Ponta Grossa, 2011. Disponível em: 〈http://ppgect.pg.utfpr.edu.br/site/wp-content/uploads/2013/09/19.zip〉. Acesso em: 30 jun. 2016.

REILY, L. Escola inclusiva: Linguagem e mediação. Campinas: PAPIRUS. 2004.

SÁ, E. D. de; CAMPOS, I. M.; SILVA, M. B. C. Atendimento educacional especializado: deficiência visual. Brasília: Ministério da Educação, Secretaria de Educação Especial. 2007.

SALAMANCA. Declaração de Salamanca: Sobre Princípios, Políticas e Práticas na Área das Necessidades Educativas. Especiais. Disponível em: <http://portal.mec. gov.br/seesp/arquivos/pdf/salamanca.pdf >. Acesso em: 30 jun. 2016.

SANCHES, S. M. Guia pedagógico de atividades para o ensino de geometria com a utilização de caleidociclos. Tese (Mestrado em Ensino de Ciência e Tecnologia) - Universidade Tecnológica do Paraná, Ponta Grossa, 2012. Disponível em: <http://ppgect.pg.utfpr.edu.br/site/wp-content/uploads/2013/09/37.zip〉. Acesso em: 30 jun. 2016. 
SEMMER, S. O ensino de arte e matemática: abordagens geométricas. Tese (Mestrado em Ensino de Ciência e Tecnologia) - Universidade Tecnológica do Paraná, Ponta Grossa, 2013. Disponível em: <http://ppgect.pg.utfpr.edu.br/site/wp-content/ uploads/2013/09/62-Simone-Semmer.rar $>$. Acesso em: 30 jun. 2016.

SHIRLO, A. C. Caderno pedagógico: auxiliando o processo de ensino-aprendizagem da geometria. Tese (Mestrado em Ensino de Ciência e Tecnologia) - Universidade Tecnológica do Paraná, Ponta Grossa, 2009. Disponível em: <http://ppgect.pg.utfpr. edu.br/site/wp-content/uploads/2013/09/3.zip>. Acesso em: 30 jun. 2016.

SILVA, L. M. S. Matemática em quadrinhos para cegos e videntes. In: Actas Del VIICIBEM - Congresso Ibero Americano de Educação Matemática. Montevidéu, Uruguai, 2013.

SZUMSKI, E. G. Manual didático para a aplicação da oficina: a bandeira nacional. Tese (Mestrado em Ensino de Ciência e Tecnologia) - Universidade Tecnológica do Paraná, Ponta Grossa, 2011. Disponível em: <http://ppgect.pg.utfpr.edu.br/ site/wp-content/uploads/2013/09/21.zip〉. Acesso em: 30 jun. 2016.

UNICENTRO. Universidade Estadual do Centro-Oeste. Caderno de provas: 1. vestibular de 2014. Guarapuava, Paraná, Brasil, 2013.

WALICHINSKI, D. Sequência de ensino contemplando a estatística nos anos finais do ensino fundamental segundo pressupostos da contextualização. Tese (Mestrado em Ensino de Ciência e Tecnologia) - Universidade Tecnológica do Paraná, Ponta Grossa, 2012. Disponível em: <http://ppgect.pg.utfpr.edu.br/site/wp-content/ uploads/2013/09/54.zip >. Acesso em: 30 jun. 2016.

Recebido: 17/06/2016

Received: 06/17/2016

Aprovado: 05/08/2016 Approved: 08/05/2016 
